\title{
Patient-reported outcome after oncoplastic breast surgery compared with conventional breast-conserving surgery in breast cancer
}

\author{
Michael Rose ${ }^{1,2}(0) \cdot$ Henry Svensson ${ }^{2,3} \cdot$ Jürgen Handler ${ }^{4}$ Ute Hoyer ${ }^{5} \cdot$ Anita Ringberg $^{2,3} \cdot$ Jonas Manjer Ju $^{2,6}$
}

Received: 13 November 2019 / Accepted: 18 January 2020 / Published online: 27 January 2020

(c) The Author(s) 2020

\begin{abstract}
Introduction Oncoplastic breast surgery (OBS) has developed as an extension of breast-conserving surgery (BCS) in an effort to improve esthetic and functional outcome following surgery for breast cancer. The aim of the present study was to evaluate the possible benefits of OBS, as compared with BCS, with regard to health-related quality of life (HRQoL), using patient-reported outcome measures (PROMs).

Patients and methods Patients treated with OBS $(n=200)$ and BCS $(n=1304)$ in the period 1 January 2008 to 31 December 2013 were identified in a research database and in the Danish Breast Cancer Cooperative Group (DBCG) registry. Data on patient, tumor, and treatment characteristics were retrieved from the DBCG registry. Patients were sent a survey including the Breast- $\mathrm{Q}^{\mathrm{TM}} \mathrm{BCT}$ postoperative module and a study-specific questionnaire (SSQ) in 2016. A good outcome in the Breast-Q module was defined as above the median. OBS was compared to BCS using a logistic regression analysis, and then adjusted for potential confounders, yielding odds ratios (OR) with $95 \%$ confidence intervals.

Results There was a statistically significant better outcome considering the HRQoL domain "Psychosocial Well-being " for patients treated with OBS as compared with BCS (OR 2.15: 1.25-3.69). No statistically significant differences were found for the domains "Physical Well-being" (0.83: 0.50-1.39), "Satisfaction with Breast" (0.95: 0.57-1.59), or "Sexual Wellbeing" (1.42: 0.78-2.58).

Conclusion The present study indicates better outcomes of HRQoL for breast cancer patients treated with OBS as compared to patients treated with BCS. There was no increase in physical discomfort among OBS patients despite more extensive surgery.
\end{abstract}

Keywords Oncoplastic breast surgery $\cdot$ Breast conserving surgery $\cdot$ Patient-reported outcome $\cdot$ Breast-Q $\cdot$ Breast cancer

Michael Rose

michael.rose@rsyd.dk

1 Department of Surgery, Section of Plastic Surgery, Hospital of Southwest Jutland, Finsensgade 35, 6700 Esbjerg, Denmark

2 Department of Clinical Sciences Malmö, Lund University, Malmö, Sweden

3 Department of Plastic and Reconstructive Surgery, Skåne University Hospital, Malmö, Sweden

4 Department of Surgery, Section of Breast Surgery, Hospital of South Jutland, Ảbenrå, Denmark

5 Department of Breast Surgery, Ålborg University Hospital, Ålborg, Denmark

6 Department of Surgery, Skåne University Hospital, Malmö, Sweden

\section{Introduction}

Breast-conserving surgery (BCS) followed by adjuvant radiotherapy, is documented to be equal to mastectomy with regard to oncological outcomes [1-3], and has to a large extent replaced total mastectomy in the last few decades. Oncoplastic breast surgery (OBS) was developed with the aim of further improving the esthetic and functional outcomes of BCS [4-7], as these affect health-related quality of life (HRQoL). However, only a few studies have addressed patient-reported outcomes (PROs), e.g., physical and psychosocial well-being, following OBS or among patients treated with conventional BCS $[8,9]$.

Several studies have evaluated oncoplastic surgery as a concept $[4,5,7,10]$, others have considered surgical techniques $[4,10]$, postoperative complications $[6,10,11]$, as well as oncological $[6,11,12]$ and esthetical outcomes $[6$, 


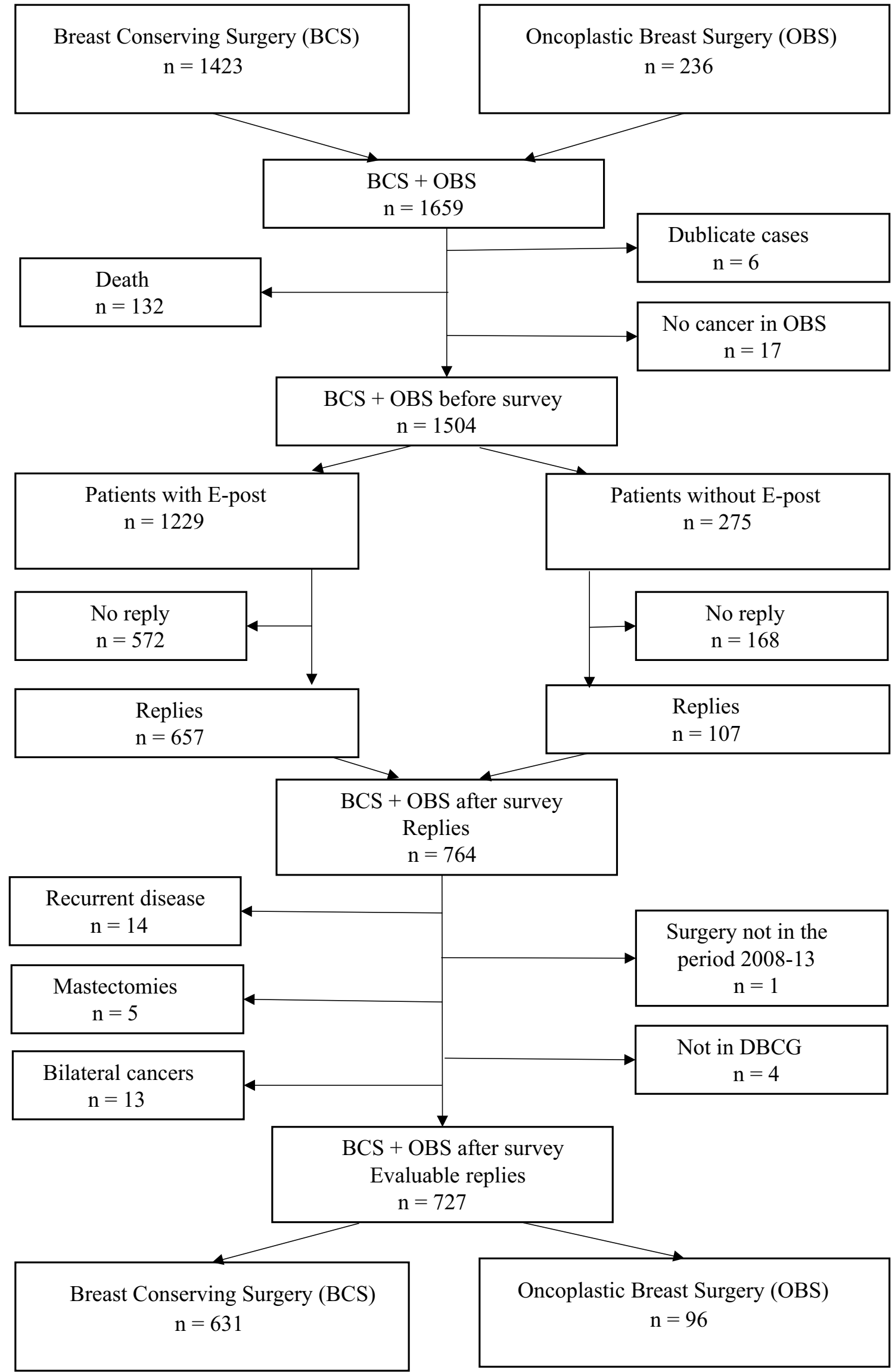


४Fig. 1 Breast-Conserving Surgery (BCS) and Oncoplastic Breast Surgery (OBS) cohorts

11, 13-15]. With the development of the Breast-Q ${ }^{\mathrm{TM}}[16$, 17] and recently the Breast- $\mathrm{Q}^{\mathrm{TM}} \mathrm{BCT}$ module, a validated instrument for patient-reported outcome measures (PROMs) is now available.

OBS can be defined as level I and level II surgical techniques [7, 18] and OBS can be considered as an extension of conventional BCS [10]. By applying OBS in BCS, a larger number of patients may achieve good esthetic and functional outcomes, and some may also escape mastectomy [6, 7, 11, $19,20]$.

The aim of this study was to investigate whether OBS improves HRQoL in patients undergoing BCS. For this purpose, we used the Breast- $\mathrm{Q}^{\mathrm{TM}} \mathrm{BCT}$ module.

\section{Materials and methods}

\section{Patients}

Patients treated for invasive primary breast cancer in the period 1 January 2008 to 31 December 2013 were recruited from two cohorts. Patients in the OBS cohort $(n=236)$ were mainly recruited from the Southern Region of Denmark, while patients in the control cohort, the BCS cohort $(n=1423)$, were recruited from the Northern Region of Denmark. Clinical data were collected from the Danish Breast Cancer Cooperative Group registry (DBCG registry) [21] and the Danish Cause of Death Registry (DAR) [22]. In 2016, patients were sent a survey including the Breast- $Q^{\mathrm{TM}}$ BCT postoperative module and a study-specific questionnaire (SSQ).

\section{Oncoplastic breast surgery cohort}

Patients treated with OBS were consecutively registered in the research database at the Hospital of Southwest Jutland, which is approved by the Danish Data Protection Agency [23], and 236 patients were registered (Fig. 1). Of these, 17 patients were not registered in the research database with primary invasive breast cancer and 6 cases were double entries to the database. According to data from the Danish Cause of Death Registry (DAR) [22] 13 patients had died at the time of the survey. In all, 200 patients remained in the OBS cohort at the time of the survey.

Patients in the OBS cohort were treated with either level I or II oncoplastic surgery [7, 18]. In this study, we define level I OBS as the adaptation of glandular tissue with minor mobilization of glandular tissue with or without repositioning of the NAC, and Level II OBS as reduction (therapeutic) mammoplasty, volume displacement and volume replacement techniques. The latter include reconstructions with perforator-based flaps [24, 25] and muscle sparing latissimus dorsi flaps [26]. Furthermore, the majority of the patients treated with level II surgery, i.e., patients who had a therapeutic mammoplasty or reconstruction using displacement techniques, had simultaneous contralateral surgery to achieve symmetry. Patients operated with mastectomy followed by an immediate autologous or implant reconstruction were not included in this study.

\section{Breast-conserving surgery cohort}

All patients diagnosed with primary invasive breast cancer treated with BCS in the Region of Northern Denmark from 1 January 2008 to 31 December 2013 were identified as a consecutive population-based cohort in the national DBCG registry [21] ( $n=1423)$ (Fig. 1). Data from the Danish Cause of Death Registry (DAR) [22] showed that 119 patients had died at the time of the survey, and in all, 1304 patients remained in the BCS cohort. OBS was not implemented in the Northern Region of Denmark as a routine surgical procedure during the study period.

\section{Patient survey}

The survey included the Breast- $\mathrm{Q}^{\mathrm{TM}} \mathrm{BCT}$ postoperative module and a study-specific questionnaire (SSQ). The SSQ included the completion of an informed consent and selected patient characteristics. Patients included in the remaining OBS and the BCS cohorts were sent the survey $(n=1504)$. A digital letter was posted to the patients in March 2016 from the Hospital of Southwest Jutland by E-post with information on the research project and a digital link to the survey $(n=1229)$. E-post is a Danish web-application developed for secure digital communication between citizens, companies and public authorities i.e., the health care system. E-post is compulsory in Denmark for all citizens, although some citizens are allowed to have only a postal address, e.g., due to lack of computer skills. A reminder was sent after four weeks to patients who had not answered. Patients who were not available by E-post were simultaneously mailed a letter with the same survey in paper form to their postal address $(n=275)$. No reminder was sent in their cases. Data were collected using the Research Electronic Data Capture (REDCap) [27] database, designed for this study. Access to REDCap [27] was licensed by the Odense Patient data Explorative Network (OPEN) University of Southern Denmark [28]. Surveys returned in paper form were transferred to the REDCap [27] database. 


\section{Study population}

In all, 764 patients replied the survey. Based on a second DBCG registry dataset form, 2017 patients were excluded if they at the time of the survey had had recurrence of the disease, a secondary mastectomy were registered with bilateral cancer, did not have surgery in the period 2008 to 2013 or if the patients were not registered in the DBCG registry (Fig. 1).

In the BCS and the OBS cohorts there were 631 and 96 evaluable replies, respectively. The total response rate for evaluable replies was $48.3 \%$ (727/1504), while the response rates for the BCS and OBS cohorts were 48.4\% (631/1304) and $48.0 \%$ (96/200), respectively.

Patients in the BCS cohort underwent surgery in the Northern region of Denmark. Patients in the OBS cohort underwent surgery in the Region of Southern Denmark at the Hospital of Southwest Jutland, Esbjerg, (1 January 2008-31 December 2013; $n=40$ ), at the Hospital of South Jutland, Aabenraa (1 October 2010-31 December 2013; $n=48$ ), or at Privathospitalet Hamlet, Copenhagen (1 January 2008-31 December 2010; $n=8$ ). Among patients in the OBS cohort, 32 had level I surgery. Sixty-four patients had level II surgery and 32 of them had contralateral surgery for symmetry. The mean follow-up time among all 727 patients was 60.8 months (range 26-100).

\section{Danish breast cancer cooperative group registry}

The national clinical database, the DBCG registry [21], includes data from all departments of radiology, breast surgery, pathology and oncology in Denmark involved in the diagnosis and treatment of breast cancer. Data include information on patient age, type of breast cancer diagnosis, time of diagnosis, tumor characteristics, surgical treatment, oncological adjuvant therapy and information on recurrent disease and death. The use of oncoplastic surgical techniques has been registered since 1 July 2010. With the permission of the Danish Clinical Registries [29], the Danish National Board of Health [29], data for patients in the OBS cohort and the BCS cohort, were identified in the DBCG registry [21]. The present study used data for the patients until 3 January 2017. We used one data set retrieved in 2014 and one retrieved in 2017. Data from 2014 were used to identify patients in the BCS cohort in the DBCG registry [21] with primary breast cancer. Data from 2017 were used to exclude replies from patients who at the time of the survey had had a recurrent disease, bilateral cancer, a mastectomy, did not have surgery in the period 2008 to 2013 or were not registered in the DBCG registry. Data on patient, tumor, and treatment characteristics were also retrieved from the DBCG registry from 2017.
Patient-reported Outcome Measure (PROM) —the Breast- $Q^{\text {Tm }}$

The Breast- $\mathrm{Q}^{\mathrm{TM}}$ is a disease-specific validated questionnaire for evaluating PRO [16]. The linguistically validated Danish version of the Breast- $\mathrm{Q}^{\mathrm{TM}} \mathrm{BCT}$ postoperative module includes 10 domains. In the present study, we selected the domains with regard to the patient-reported outcome of treatment, namely "Satisfaction with breast", "Psychosocial Well-being", "Sexual Well-being" and "Physical Wellbeing". Permission to use the Danish version of the questionnaire was granted by the MAPI Research Trust Institute [30] which administers the Breast- $Q^{\mathrm{TM}}$. Breast- $\mathrm{Q}^{\mathrm{TM}}$ data are transformed into scores ranging from 0 to 100 according to the guidelines for the Breast-Q postoperative module. Higher scores represent more favorable outcomes.

\section{Characteristics of patients, tumors, and treatments}

Several factors may affect the patient-reported outcome. In the present analysis, we used the a priori selected patient characteristics: age at surgery, follow-up time, menopausal status, chest measurement, bra cup-size, BMI, smoking habits, as well as marital status, education and living arrangement. Furthermore, the following tumor and treatment characteristics were selected: TNM-classification, lumpectomy size, tumor location, radiotherapy, chemotherapy, endocrine therapy and immunotherapy, and axillary surgery. These data were mainly collected from the DBCG registry [21] whereas complementary data were collected from the SSQ.

\section{Statistical methods}

The OBS and BCS cohorts were compared using univariate logistic regression analyses for the scores for each domain in the Breast-Q BCT module. The analyses were conducted separately for the OBS cohort including level I and II oncoplastic procedures and for the OBS cohort only including level II procedures. The scores in the Breast-Q domains (0-100) for the BCS cohort were transformed from a linear variable into a binary variable by the median score used for the cut-off value for each domain as the dependent variable, i.e., scores lower than the median score were considered less favorable and higher scores as more favorable. The risk of a better outcome was compared between the OBS and BCS cohorts as the logistic regression analysis yielded odds ratios (OR) with $95 \%$ confidence intervals. Factors that might affect the patient-reported outcome, i.e., patient, tumor and treatment characteristics, were selected à priori and included in a second multivariate logistic regression model. We performed sensitivity analyses excluding patients registered in the DBCG registry as treated with OBS from 1 July 2010 to 31 December 2013 in the BCS cohort $(n=24)$. We also 
compared responders $(n=727)$ to non-responders $(n=683)$ in order to check for potential selection bias. This analysis included age at surgery and the same tumor characteristics and treatment factors as used in the analyses of responding patients. Data were analyzed using IBM-SPSS Statistics version 24.0, IBM Corp., US.

\section{Ethics}

The study was approved by The Regional Committee on Health Research Ethics for Southern Denmark. The study was submitted for evaluation to The Regional Ethical Review Board in Lund, Sweden, as the research was conducted at Lund University, Sweden, but their approval was not required (Dnr.2014/882). The research database identifying OBS patients was approved by the Danish Data Protection Agency [23].

\section{Results}

\section{Patient, tumor, and treatment factors}

Compared with the BCS cohort, patients in the OBS cohort were younger, more often never-smokers or non-smokers at the time of surgery, and had a lower BMI (Table 1). Notably, they had larger tumors, larger lumpectomies, were more often treated with chemotherapy, endocrine therapy and axillary clearance, and nearly all had been treated with radiotherapy (Table 2). This indicates that the patients in the OBS cohort had more advanced cancers than those in the BCS cohort.

\section{Psychosocial well-being}

The median score for the domain "Psychosocial Well-being" was 82 with a response rate of $99.3 \%$. There was a better outcome for the OBS cohort (OR 2.15: 1.25-3.69) (Table 3). When comparing the OBS cohort including only level II oncoplastic surgery with the BCS cohort, we found a difference that was even stronger (OR 2.67: 1.37-5.20).

\section{Physical well-being}

The median score for "Physical Well-being" was 78 with a response rate of $98.7 \%$. There was no statistically significant difference between OBS and BCS patients as the OR was $0.83(0.50-1.39)$ (Table 3$)$. When only level II surgery was included in OBS, the OR was even closer to $1.00(0.94$ : $0.50-1.74)$.
Table 1 Patient characteristics

\begin{tabular}{|c|c|c|c|c|}
\hline Covariates & Category & $\begin{array}{l}\text { BCS } \\
n=631 \\
\text { Column }\end{array}$ & $\begin{array}{l}\text { OBS } \\
n=96 \\
\text { percent* }\end{array}$ & $\begin{array}{l}\text { Total } \\
n=727\end{array}$ \\
\hline \multirow[t]{3}{*}{ Age at surgery (year) } & $<50$ & 15.5 & 25.0 & 16.8 \\
\hline & $\geq 50$ to $<65$ & 56.6 & 52.1 & 56.0 \\
\hline & $\geq 65$ & 27.9 & 22.9 & 27.2 \\
\hline \multirow[t]{2}{*}{ Menopause } & Premenopausal & 23.6 & 34.4 & 25.0 \\
\hline & Postmenopausal & 73.9 & 63.5 & 72.5 \\
\hline \multirow[t]{7}{*}{ Bra size } & A & 8.7 & 13.5 & 9.4 \\
\hline & $\mathrm{B}$ & 31.2 & 26.0 & 30.5 \\
\hline & $\mathrm{C}$ & 26.1 & 24.0 & 25.9 \\
\hline & $\mathrm{D}$ & 18.5 & 16.7 & 18.3 \\
\hline & $\mathrm{E}$ & 4.1 & 6.3 & 4.4 \\
\hline & $\geq \mathrm{F}$ & 5.1 & 8.3 & 5.5 \\
\hline & Missing & 6.2 & 5.2 & 6.1 \\
\hline \multirow{6}{*}{$\begin{array}{l}\text { Chest measurement } \\
(\mathrm{cm})\end{array}$} & $\leq 82$ & 20.9 & 21.9 & 21.0 \\
\hline & $83-87$ & 20.0 & 25.0 & 20.6 \\
\hline & $88-92$ & 13.8 & 15.6 & 14.0 \\
\hline & $93-97$ & 8.4 & 7.3 & 8.3 \\
\hline & $\geq 98$ & 15.1 & 10.4 & 14.4 \\
\hline & Missing & 21.9 & 19.8 & 21.6 \\
\hline \multirow[t]{4}{*}{ BMI } & $<25$ & 36.8 & 41.7 & 37.4 \\
\hline & $25.0-29.9$ & 35.3 & 39.6 & 35.9 \\
\hline & $\geq 30$ & 17.6 & 16.7 & 17.5 \\
\hline & Missing & 10.3 & 2.1 & 9.2 \\
\hline \multirow[t]{2}{*}{ Ever smoker } & Non-smoker & 40.6 & 57.3 & 42.8 \\
\hline & Smoker & 53.3 & 42.7 & 53.6 \\
\hline \multirow[t]{2}{*}{ Smoking at surgery } & Non-smoker & 77.7 & 86.5 & 78.8 \\
\hline & Smoker & 19.5 & 13.5 & 18.7 \\
\hline \multirow[t]{5}{*}{ Marital status } & Single & 7.9 & 11.5 & 8.4 \\
\hline & Married & 68.3 & 69.8 & 68.5 \\
\hline & Separated & 0.6 & 1.0 & 0.7 \\
\hline & Divorced & 9.2 & 10.4 & 9.4 \\
\hline & Widow & 13.3 & 7.3 & 12.5 \\
\hline \multirow[t]{3}{*}{ Living arrangement } & Living alone & 23.6 & 18.8 & 23.0 \\
\hline & Cohabiting & 69.6 & 77.1 & 70.6 \\
\hline & Others & 3.2 & 1.0 & 2.9 \\
\hline \multirow[t]{5}{*}{ Educational level (year) } & Primary school & 20.8 & 12.5 & 20.6 \\
\hline & Secondary school & 10.0 & 12.5 & 10.3 \\
\hline & Short (2) & 32.3 & 22.9 & 31.1 \\
\hline & Medium (3-4) & 31.9 & 37.5 & 32.6 \\
\hline & Higher (3-6) & 4.3 & 7.3 & 4.7 \\
\hline
\end{tabular}

*Column percent does not always add up to $100 \%$ as missing data are only shown if $>5 \%$

\section{Satisfaction with breast}

The median score for the domain "Satisfaction with Breast" was 74 with a response rate of $99.2 \%$. The adjusted OR showed no statistically significant difference between the 
Table 2 Tumor characteristics and treatment factors

\begin{tabular}{|c|c|c|c|c|}
\hline Covariates & Category & $\begin{array}{l}\text { BCS } \\
n=631 \\
\text { Column }\end{array}$ & $\begin{array}{l}\text { OBS } \\
n=96 \\
\text { percent }\end{array}$ & $\begin{array}{l}\text { Total } \\
n=727 \\
*\end{array}$ \\
\hline \multirow[t]{3}{*}{ Tumor size } & $\mathrm{T} 1 \leq 20 \mathrm{~mm}$ & 84.0 & 62.5 & 81.2 \\
\hline & $\mathrm{T} 2$ 21-50 mm & 15.7 & 34.4 & 18.2 \\
\hline & $\mathrm{T} 3 \geq 50 \mathrm{~mm}$ & 0.3 & 0.0 & 0.3 \\
\hline \multirow{4}{*}{$\begin{array}{l}\text { Lumpectomy size } \\
\left(\mathrm{cm}^{3}\right)\end{array}$} & $<50$ & 20.0 & 15.6 & 19.4 \\
\hline & $50-99$ & 30.7 & 26.0 & 30.1 \\
\hline & 100-199 & 33.0 & 32.3 & 32.9 \\
\hline & $\geq 200$ & 14.9 & 21.9 & 15.8 \\
\hline \multirow[t]{6}{*}{ Tumor location } & Upper lateral & 37.9 & 40.6 & 38.2 \\
\hline & Upper medial & 14.6 & 8.3 & 13.8 \\
\hline & Lower lateral & 8.9 & 9.4 & 8.9 \\
\hline & Lower medial & 7.0 & 6.3 & 6.9 \\
\hline & Central & 6.2 & 15.6 & 7.4 \\
\hline & Overlapping regions & 23.8 & 19.8 & 23.2 \\
\hline \multirow[t]{2}{*}{ Axillary dissection } & No & 66.2 & 52.1 & 64.4 \\
\hline & Yes & 33.8 & 44.8 & 35.2 \\
\hline \multirow[t]{2}{*}{ Radiotherapy } & No & 4.4 & 2.1 & 4.1 \\
\hline & Yes & 95.6 & 97.9 & 95.9 \\
\hline \multirow[t]{2}{*}{ Chemotherapy } & No & 58.6 & 49.0 & 57.4 \\
\hline & Yes & 41.4 & 51.0 & 42.6 \\
\hline \multirow[t]{2}{*}{ Endocrine therapy } & No & 42.3 & 34.4 & 41.3 \\
\hline & Yes & 57.7 & 65.6 & 58.7 \\
\hline \multirow[t]{2}{*}{ Immune therapy } & No & 91.1 & 89.6 & 90.9 \\
\hline & Yes & 8.9 & 10.4 & 9.1 \\
\hline
\end{tabular}

*Column percent does not always add up to 100 as missing data are not shown

OBS cohort and the BSC cohort (Table 3). This was also true when only level II OBS patients were considered.

\section{Sexual Well-being}

The median score for the domain "Sexual Well-being" was 58 with a response rate of only $69.6 \%$. There was no statistically significant difference between OBS and BCS (Table 3). Including only level II surgery indicated a slightly better outcome in the OBS group, although not statistically significant (OR 1.86: 0.90-3.83).

\section{Sensitivity analysis and analysis comparing responders with non-responders}

Sensitivity analysis excluding patients from the BCS cohort who were registered in the DBCG registry as treated with OBS in the period 1 July 2010 to 31 December $2013(n=24)$, showed all the same results (data not shown). Responders and non-responders were very similar with regard to age, tumor characteristics and treatment factors (Table 4).

\section{Discussion}

In this study, we evaluated the outcome of OBS compared with BCS using the Breast- $\mathrm{Q}^{\mathrm{TM}} \mathrm{BCT}$ postoperative module. We found that patients treated with OBS had a better "Psychosocial Well-being ". However, no significant differences were found for the domains "Physical Wellbeing", "Satisfaction with Breast" or "Sexual Well-being".

Evaluation of surgical treatment of breast cancer by oncological outcomes remains essential. However, the quality of the health care services provided also needs attention. There is now an increasing demand to evaluate how patients perceive the results of treatment, i.e., PRO $[8,9,19]$. In this study we took advantage of Breast- $\mathrm{Q}^{\mathrm{TM}}$ which can be used as a standardized and validated instrument for evaluation of HRQoL in patients operated for breast cancer [16, 31-33].

Although the esthetic and functional outcome of OBS compared with BCT has been investigated before [15], there have been few studies comparing HRQoL between OBS and $\mathrm{BCS}$ so far. The Breast- $\mathrm{Q}^{\mathrm{TM}} \mathrm{BCT}$ pre- and postoperative module was introduced in 2015. One year later, $\mathrm{O}^{\prime}$ Connell et al. [8] published their initial experience with the full BCT postoperative module including 200 patients, thus establishing a benchmark for future research. However, few studies have addressed the HRQoL outcome of BCS $[8,9,16]$ and OBS [34] or both. Compared with previous studies, patients included in the OBS cohort in this study represent the full spectrum of OBS, i.e., level I and II surgery, and the sample is therefore not restricted to one surgical procedure such as the therapeutic mammoplasty technique [34].

In the domain "Psychosocial Well-being" we found a median score of 82, similar to the results of O'Connell [8] and Dahlbäck [35], using Breast-Q ${ }^{\mathrm{TM}}$ for evaluation of the outcome of BCT, while Langendiik [36] found a mean score at 70.1 and Vesprini [9] found a mean score at 73.5. In our study we found a statistically significant better outcome for the OBS cohort, including level I and II surgery, compared with the BCS cohort. The difference was strengthened by including only level II surgery from the OBS cohort.

In their analyses of the domain "Physical Well-being" after BCT with Breast-Q ${ }^{\mathrm{TM}}$, Langendjik [36] and Vesprini [9] found mean scores of 71.2 and 74, respectively. A slightly higher score of 75 was reported by O Connell [8]. The median score of 78 in this study reflects a low grade of physical discomfort and there was no statistically significant difference between OBS and BCT. One could have expected a lower score for the OBS cohort, particularly in cases of level II surgery as this surgery is more extensive and often involves the contralateral breast. On the contrary, there was a slight difference in the figures, indicating better outcomes for OBS compared with BCS. 
Table 3 Odds ratios for and adjusted odds ratios for scores in Breast-Q modules "Psychosocial Well-being", "Physical Well-being", "Sexual Well-being", and "Satisfaction with Breasts" for BSC and OBS level I+ II and BCS and OBS level II

\begin{tabular}{|c|c|c|c|c|c|c|}
\hline Domain & Cohort & All & Below median & Above median & OR & $\mathrm{OR}^{\mathrm{a}}$ \\
\hline Psychosocial Well-being & BCS & 627 & 311 & 316 & 1.00 & 1.00 \\
\hline \multirow[t]{3}{*}{ Median $=82$} & OBS level I+II & 95 & 38 & 57 & $1.48(0.95-2.29)$ & $2.15(1.25-3.69)$ \\
\hline & $\mathrm{BCS}$ & 627 & 311 & 316 & 1.00 & 1.00 \\
\hline & OBS level II & 63 & 23 & 40 & $1.71(1.00-2.96)$ & $2.67(1.37-5.20)$ \\
\hline Physical Well-being & BCS & 623 & 277 & 346 & 1.00 & 1.00 \\
\hline \multirow[t]{3}{*}{ Median $=78$} & OBS level I+II & 95 & 50 & 45 & $0.72(0.47-1.11)$ & $0.83(0.50-1.39)$ \\
\hline & BCS & 623 & 277 & 346 & 1.00 & 1.00 \\
\hline & OBS level II & 63 & 32 & 31 & $0.78(0.46-1.30)$ & $0.94(0.50-1.74)$ \\
\hline Satisfaction with Breast & BCS & 626 & 308 & 318 & 1.00 & 1.00 \\
\hline \multirow[t]{3}{*}{ Median $=74$} & OBS level I+II & 95 & 48 & 47 & $0.94(0.61-1.45)$ & $0.95(0.57-1.59)$ \\
\hline & BCS & 626 & 308 & 318 & 1.00 & 1.00 \\
\hline & OBS level II & 63 & 29 & 34 & $1.13(0.67-1.90)$ & $1.25(0.67-2.33)$ \\
\hline Sexual Well-being & BCS & 431 & 205 & 226 & 1.00 & 1.00 \\
\hline \multirow[t]{3}{*}{ Median $=58$} & OBS level I+II & 75 & 33 & 42 & $1.15(0.71-1.89)$ & $1.42(0.78-2.58)$ \\
\hline & BCS & 431 & 205 & 226 & 1.00 & 1.00 \\
\hline & OBS level II & 50 & 21 & 29 & $1.25(0.69-2.27)$ & $1.86(0.90-3.83)$ \\
\hline
\end{tabular}

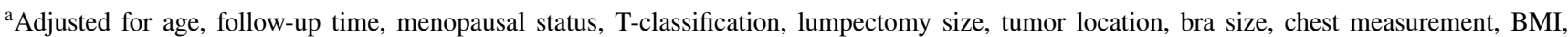
radiotherapy, chemotherapy, endocrine therapy, immunotherapy, axillary clearance, smoking, marital status, living arrangement and education

In the analysis of the domain "Satisfaction with Breast" Vesprini [9] and Langendjik [36] found mean scores of 59.3 and 65.7, respectively, while Dahlbäck [35] and O'Connell [8] found median scores of 66 and 68, respectively. Hence, our median score of 74 in the present study means our scores are higher than those reported previously and they indicate a higher degree of satisfaction with the breast. High scores generally imply that possible differences are difficult to detect and, consequently, we found no difference between OBS and BCS. However, when only level II surgery was considered, a tendency toward a better outcome in the OBS group was noted.

The domain "Sexual Well-being" had a markedly lower median score of 58 and, furthermore, the response rate was low at $69.6 \%$. This pattern has also been seen in previous studies investigating BCT $[8,9,36]$, and it seems to be a general issue for this domain. Therefore, results must be interpreted with caution. We found no difference between OBS and BCS. However, when only level II surgery was considered, a slight tendency toward a better outcome in the OBS group was noted.

In summary, the results show that patients treated with OBS reported statistically better psychosocial health than those treated with BCS. Patients treated with OBS also scored slightly higher for the domains "Satisfaction with breasts" and "Sexual Well-being" particularly when the analyses only included level II OBS, although the difference was not statistically significant. Notably, the results in the domain "Physical Well-being" showed no significant differences despite the fact that patients treated with OBS had more extensive and often bilateral surgery.

A methodological issue to be considered is the definition of OBS. In studies published in the last few decades, the definition of OBS has varied, making it difficult to compare the outcome results from different studies. In the present study, we have based our definition on that proposed by Clough et al. [7], which is widely accepted. In the publication by Chatterjee et al. [18], a consensus definition and classifications system, developed by the American Society of Breast Surgeons, was presented which was strongly influenced by Clough's definition [7]. By using a widely accepted definition of OBS we hope that the results from the present study can be used for comparison with future studies.

Another methodological issue to be considered is the PROM instrument chosen. The Breast- $\mathrm{Q}^{\mathrm{TM}} \mathrm{BCT}$ module is now widely accepted as a valuable PROM instrument for breast-conserving surgery [31, 32 37], which is why we have chosen the Breast- $\mathrm{Q}^{\mathrm{TM}} \mathrm{BCT}$ postoperative module.

Furthermore, the validity of the data used must be considered. Data in the research database were only used for identification of patients treated with OBS. To avoid misclassification of patient, tumor and treatment characteristics, all data for both the OBS and the BCS cohorts were obtained from the national DBCG registry [21]. In a recent study by Cronin-Fenton et al., [38] the authors conclude that DBCG data are valid for epidemiological studies of breast cancer treatment; thus, we believe that the validity of the data is good. 
Table 4 Patient and tumor characteristics and treatment factors for the responder and non-responder cohorts

\begin{tabular}{|c|c|c|c|c|c|}
\hline \multirow[t]{4}{*}{ Covariates } & \multirow[t]{4}{*}{ Category } & \multicolumn{2}{|l|}{ OBS } & \multicolumn{2}{|l|}{ BCS } \\
\hline & & Responders & Non-responders & Responders & Non-responders \\
\hline & & $n=96$ & $n=71$ & $n=631$ & $n=612$ \\
\hline & & \multicolumn{4}{|c|}{ Column percent* } \\
\hline \multirow[t]{3}{*}{ Age at surgery (years) } & $<50$ & 25.0 & 18.3 & 15.5 & 12.7 \\
\hline & $\geq 50$ to $<65$ & 52.1 & 52.1 & 56.6 & 50.0 \\
\hline & $\geq 65$ & 22.9 & 29.6 & 27.9 & 37.3 \\
\hline \multirow[t]{3}{*}{ Tumor size } & $\mathrm{T} 1 \leq 20 \mathrm{~mm}$ & 62.5 & 63.4 & 84.0 & 82.2 \\
\hline & $\mathrm{T} 221-50 \mathrm{~mm}$ & 34.4 & 33.8 & 15.7 & 17.3 \\
\hline & $\mathrm{T} 3 \geq 50 \mathrm{~mm}$ & 0.0 & 0.0 & 0.3 & 0.3 \\
\hline \multirow[t]{4}{*}{ Lumpectomy size $\left(\mathrm{cm}^{3}\right)$} & $<50$ & 15.6 & 12.7 & 20.0 & 20.9 \\
\hline & $50-99$ & 26.0 & 32.4 & 30.7 & 27.8 \\
\hline & $100-199$ & 32.3 & 26.8 & 33.0 & 30.9 \\
\hline & $\geq 200$ & 21.9 & 25.4 & 14.9 & 17.5 \\
\hline \multirow[t]{6}{*}{ Tumor location } & Upper lateral & 40.6 & 32.4 & 37.9 & 41.0 \\
\hline & Upper medial & 8.3 & 12.7 & 14.6 & 11.4 \\
\hline & Lower lateral & 9.4 & 11.3 & 8.9 & 10.8 \\
\hline & Lower medial & 6.3 & 12.7 & 7.0 & 6.2 \\
\hline & Central & 15.6 & 7.0 & 6.2 & 5.4 \\
\hline & $>1$ region & 19.8 & 22.5 & 23.8 & 22.1 \\
\hline \multirow[t]{2}{*}{ Axillary dissection } & No & 52.1 & 59.2 & 66.2 & 64.1 \\
\hline & Yes & 44.8 & 39.4 & 33.8 & 35.8 \\
\hline \multirow[t]{2}{*}{ Radiotherapy } & No & 2.1 & 5.6 & 4.4 & 4.2 \\
\hline & Yes & 97.9 & 94.4 & 95.6 & 95.8 \\
\hline \multirow[t]{2}{*}{ Chemotherapy } & No & 49.0 & 56.3 & 58.6 & 69.4 \\
\hline & Yes & 51.0 & 43.1 & 41.4 & 30.6 \\
\hline \multirow[t]{2}{*}{ Endocrine therapy } & No & 34.4 & 35.2 & 42.3 & 40.8 \\
\hline & Yes & 65.6 & 64.8 & 57.7 & 59.2 \\
\hline \multirow[t]{2}{*}{ Immune therapy } & No & 89.6 & 90.1 & 91.1 & 94.3 \\
\hline & Yes & 10.4 & 9.9 & 8.9 & 5.7 \\
\hline
\end{tabular}

*Column percent does not always add up to 100 as missing data are not shown. Patients in the Responder cohort $(n=764)$ and Non-responder cohort $(n=1504-764=740)$ were excluded (Responder cohort $(n=37)$ and Non-responder cohort $(n=57)$ ) if the patients were not registered in the DBCG registry, did not have surgery in the study period, did not have breast cancer, had bilateral cancers or a secondary breast cancer (bilateral event) or if they had a recurrent disease or had undergone a mastectomy before the survey (Fig. 1)
To avoid confounding by indication, the patients in the OBS and BCS cohorts were recruited from different geographical regions. The unselected demographic BCS cohort thus also possibly included some more advanced cases that might have been selected for OBS. In the early study period, such cases were not identified, but from 1 July 2010, 24 cases could be identified in the DBCG registry. Sensitivity analyses excluding these patients did not alter the results. The OBS cohort may include patients with relatively more advanced disease, i.e., the OBS cohort could include patients with tumor and treatment characteristics known to predict less satisfying outcomes of HRQoL. By adjusting for these variables in the statistical analyses, we have reduced this potential selection bias.
Response rates in other surveys are reported to be between $31 \%$ [9] and 76\% [35]. With a total response rate in our study of $48.3 \%$ for evaluable replies (OBS cohort $48.4 \%$, BCS cohort $48.0 \%$ ) we find our response rate acceptable. The analysis comparing patients in the responder and the non-responder cohorts showed only minor differences, that is, the responder cohort is considered representative of the survey cohort, showing no selection bias. 


\section{Conclusion}

The present study indicates better outcomes of HRQoL for breast cancer patients treated with OBS as compared to patients treated with BCS. There was no increase in physical discomfort among OBS patients despite more extensive surgery.

Acknowledgements Open access funding provided by Lund University. This study was financially supported by The Malmö University Hospital Cancer Research Fund, The Einar and Inga Nilsson Foundation, Skåne University Hospital Funds and Donations and The Hospital of Southwest Jutland. The authors wish to express their gratitude to DBCG and especially Maj-Britt Jensen. The authors also wish to express their gratitude to OPEN, University of Southern Denmark. The funding sponsors had no influence on the study design, analyses of the data or the presentation.

Funding This study was financially supported by The Malmö University Hospital Cancer Research Fund, The Einar and Inga Nilsson Foundation, Region Skåne, Skåne University Hospital Funds and Donations, and The Hospital of Southwest Jutland. The funding sponsors had no influence on the study design, analyses of the data or the presentation.

\section{Compliance with ethical standards}

Conflicts of interest The authors declare that they have no conflicts of interest.

Ethical approval All procedures performed in studies involving human participants were in accordance with the ethical standards of the institutional and/or national research committee and with the 1964 Helsinki declaration and its later amendments or comparable ethical standards.

Informed consent Informed consent was obtained from all individual participants included in the study.

Open Access This article is licensed under a Creative Commons Attribution 4.0 International License, which permits use, sharing, adaptation, distribution and reproduction in any medium or format, as long as you give appropriate credit to the original author(s) and the source, provide a link to the Creative Commons licence, and indicate if changes were made. The images or other third party material in this article are included in the article's Creative Commons licence, unless indicated otherwise in a credit line to the material. If material is not included in the article's Creative Commons licence and your intended use is not permitted by statutory regulation or exceeds the permitted use, you will need to obtain permission directly from the copyright holder. To view a copy of this licence, visit http://creativecommons.org/licenses/by/4.0/.

\section{References}

1. Wolmark N et al (2002) Twenty-year follow-up of a randomized trial comparing total mastectomy, lumpectomy, and lumpectomy plus irradiation for the treatment of invasive breast cancer. $\mathrm{N}$ Engl J Med 347:1233-1241

2. Blichert-Toft $\mathrm{M}$ et al (2008) Long-term results of breast conserving surgery vs. mastectomy for early stage invasive breast cancer: 20-Year follow-up of the Danish randomized DBCG82TM protocol. Acta Oncol 47:672-681
3. Christiansen P et al (2017) Breast conserving surgery versus mastectomy: overall and relative survival-a population based study by the Danish Breast Cancer Cooperative Group (DBCG ) Supplementary material. Acta Oncol 57:1-3

4. Weber WP et al (2017) Standardization of oncoplastic breast conserving surgery. Eur J Surg Oncol 43:1236-1243

5. Berry MG, Fitoussi AD, Curnier A, Couturaud B, Salmon RJ (2010) Oncoplastic breast surgery: a review and systematic approach. J Plast Reconstr Aesth Surg 63:1233-1243

6. Campbel EJ, Romics L (2017) Oncological safety and cosmetic outcomes in oncoplastic breast conservation surgery, a review of the best level of evidence literature. Breast Cancer 9:521-530

7. Clough KB, Kaufman GJ, Nos C, Buccimazza I, Sarfati IM (2010) Improving breast cancer surgery: a classification and quadrant per quadrant atlas for oncoplastic surgery. Ann Surg Oncol 17:1375-1391

8. O'Connell RL et al (2016) Initial experience of the BREAST$\mathrm{Q}$ breast-conserving therapy module. Breast Cancer Res Treat 160:79-89

9. Vesprini D et al (2017) Patient-reported outcomes following breast conservation therapy and barriers to referral for partial breast reconstruction. Plast Reconstr Surg 141:1-9

10. Rose M, Manjer J, Ringberg A, Svensson H (2014) Surgical strategy, methods of reconstruction, surgical margins and postoperative complications in oncoplastic breast surgery. Eur J Plast Surg 37:205-214

11. Losken A, Dugal CS, Styblo TM, Carlson GW (2014) A metaanalysis comparing breast conservation therapy alone to the oncoplastic technique. Ann Plast Surg 72:145-149

12. Wang K, Huang Y-J, Zhang L-L, Chen J-Y, Yang C-Q (2018) Comparison of oncoplastic breast-conserving surgery and breast-conserving surgery alone: a meta-analysis. J Breast Cancer 21:321

13. Spautz C et al (2014) Long-term comparison of aesthetical outcomes after oncoplastic surgery and lumpectomy in breast cancer patients. Ann Surg Oncol 22:2500-2508

14. Massa M, Meszaros P, Baldelli I, Bisso N, Franchelli S (2015) Aesthetic evaluation in oncoplastic and conservative breast surgery: a comparative analysis. J Plast Reconstr Surg 3:e339

15. Ojala K, Meretoja TJ, Leidenius MHK (2017) Aesthetic and functional outcome after breast conserving surgery-comparison between conventional and oncoplastic resection. Eur J Surg Oncol 43:658-664

16. Pusic AL, Klassen AF, Scott AM, Klok JA, Cordeiro PG, Cano SJ (2009) Development of a new patient-reported outcome measure for breast surgery: The BREAST-Q. Plast Reconstr Surg 124:345-353

17. Fuzesi S, Cano SJ, Klassen AF, Atisha D, Pusic AL (2017) Validation of the electronic version of the BREAST-Q in the army of women study. Breast 33:44-49

18. Chatterjee A et al (2019) A consensus definition and classification system of oncoplastic surgery developed by the american society of breast surgeons. Ann Surg Oncol 26:3436-3444

19. Paramanathan $\mathrm{N}$ et al (2017) Patient-reported outcomes are better after oncoplastic breast conservation than after mastectomy and autologous reconstruction. Plast Reconstr Surg 5:e1419

20. Di Micco R et al (2017) Bilateral mammoplasty for cancer: surgical, oncological and patient-reported outcomes. Eur J Surg Oncol 43:68-75

21. DBCG, Danish Breast Cancer Cooperative Group. https://www. dbcg.dk/.

22. Sundhedsdatastyrelsen, Danish Cause of Death Register. https:// sundhedsdatastyrelsen.dk/da.

23. Datatilsynet, Danish Data Protection Agency. https://www.datat ilsynet.dk/. 
24. McCulley SJ, Schaverien MV, Tan VKM, Macmillan RD (2015) Lateral thoracic artery perforator (LTAP) flap in partial breast reconstruction. J Plast Reconstr Aesthetic Surg 68:686-691

25. Rose M, Svensson H (2012) Tunnelled lateral fasciocutaneous thoracodorsal flap with a skin island in breast reconstruction in oncoplastic breast surgery. J Plast Surg Hand Surg 46:404-409

26. Saint-Cyr M et al (2009) The pedicled descending branch muscle-sparing latissimus dorsi flap for breast reconstruction. Plast Reconstr Surg. https://doi.org/10.1097/PRS.0b013e3181934838

27. REDCap. https://projectredcap.org/

28. OPEN—Syddansk Universitet. https://www.sdu.dk/da/Om_SDU/ Institutter_centre/Klinisk_institut/Forskning/Forskningsenheder/ open.aspx

29. The Danish Clinical Registries, Danish National Board of Health. https://www.rkkp.dk/

30. Mapi research trust. http://mapi-trust.org/

31. Liu LQ, Branford OA, Mehigan S (2018) BREAST-Q measurement of the patient perspective in oncoplastic breast surgery. Plast Reconstr Surg 6:e1904

32. Cohen WA et al (2016) The BREAST-Q in surgical research: a review of the literature 2009-2015. J Plast Reconstr Aesth Surg 69:149-162

33. Stolpner I et al (2019) Clinical validation of the BREASTQ Breast-conserving therapy module. Ann Surg Oncol 26:2759-2767
34. Acea-Nebril B et al (2017) The role of oncoplastic breast reduction in the conservative management of breast cancer: complications, survival, and quality of life. J Surg Oncol 115:679-686

35. Dahlbäck C, Ullmark JH, Rehn M, Ringberg A, Manjer J (2017) Aesthetic result after breast-conserving therapy is associated with quality of life several years after treatment. Swedish women evaluated with BCCT.core and BREAST-Q ${ }^{\mathrm{TM}}$. Breast Cancer Res Treat 164:679-687

36. Lagendijk M et al (2018) Patient-reported outcome measures may add value in breast cancer surgery. Ann Surg Oncol 25:3563-3571

37. Morley R, Leech T (2019) Optimal assessment tools in assessing breast surgery: patient reported outcome measures (PROMs) vs objective measures. Gland Surg 8:1-9

38. Cronin-Fenton DP et al (2017) Validity of Danish Breast Cancer Group (DBCG) registry data used in the predictors of breast cancer recurrence (ProBeCaRe) premenopausal breast cancer cohort study. Acta Oncol 56:1155-1160

Publisher's Note Springer Nature remains neutral with regard to jurisdictional claims in published maps and institutional affiliations. 